\title{
Reforço Estrutural em Prédio Caixão Situado na Região Metropolitana de Recife
}

\author{
Structural Reinforcement In Box-Type Building Situated In The Metropolitan Region Of \\ Recife
}

Alexandre Lyra Marques dos Santos 1,2 Dorcid.org/0000-0002-7273-5300

Carlos Welligton P. Sobrinho 1,2 (D) orcid.org/0000-0002-6354-9178

1 Escola Politécnica de Pernambuco, Universidade de Pernambuco, Recife, Brasil,
2 Pós-graduação em Inspeção, Recuperação e Manutenção de Estruturas, Escola Politécnica de Pernambuco, Pernambuco, Brasil,
E-mail do autor principal: Alexandre Lyra M. dos Santos alexandre_lyra_pe@yahoo.com.br

\section{Resumo}

O presente trabalho tem como objetivo contribuir com a bibliografia dedicada à problemática dos prédios tipo caixão, direcionando-se à realidade da Região Metropolitana de Recife, que conta com diversos empreendimentos nos quais foram adotados o sistema construtivo de Alvenaria Resistente. Diante da necessidade de recuperação estrutural de grande parte destas edificações, o registro dos procedimentos adotados para elaboração de projetos e para execução dos serviços em nosso estudo poderá contribuir para o estabelecimento de procedimentos que possam ser aplicados a outros empreendimentos em situação semelhante.

Palavras-Chave: Prédio tipo Caixão, recuperação estrutural, Região Metropolitana de Recife

\begin{abstract}
The present work aims to contribute with the bibliography dedicated to the problem of box-type buildings, focusing on the reality of the Metropolitan Region of Recife, which has several projects in which the construction system of Resistant Masonry was adopted. In view of the need for structural recovery of a large number of these buildings, the registration of the procedures adopted for the preparation of projects and for the execution of the services in our study may contribute to the establishment of procedures that can be applied to other enterprises in a similar situation.
\end{abstract}

Key-words: Box-type building, structural restoration, Metropolitan Region of Recife 


\section{Introdução}

A partir da criação do Banco Nacional da Habitação - BNH - ocorrido na década de setenta, o mercado da Construção Civil no Brasil passou a contar com grandes incentivos.

Este fato refletiu diretamente no valor do solo nas grandes cidades do País. A maior verticalização das construções foi algo natural, diante da necessidade de obter o melhor retorno dos investimentos.

É a partir daí que se populariza a construção dos prédios do tipo caixão. A técnica adotada é denominada alvenaria resistente, constituída de blocos cerâmicos vazados assentados com os furos na horizontal ou de blocos de concreto. Os pavimentos eram intercalados com laje prémoldada ou moldada in-loco e, em todos os casos, escada moldada no local em concreto armado, com a caixa de escada aporticada ou apoiada sobre painéis de alvenaria resistente.

Durante as décadas seguintes, este sistema foi amplamente adotado por construtoras de diversos portes e por toda a região Metropolitana sem que houve qualquer restrição imposta pelo poder público.

Entretanto, a busca por redução de custos, agravada por modificações na conjuntura do mercado imobiliário, levou os construtores a adotar simplificações que resultaram em sistemas que não estavam de acordo com a boa prática de Engenharia. Itens como vergas e contravergas, por exemplo, passaram a ser negligenciados.

Esses fatores, associados à intervenções realizadas pelos próprios moradores sem o devido acompanhamento técnico, além da frequente falta de manutenção preventiva e/ou corretiva, foram determinantes para que, a partir no início da década de 1990, ocorressem diversos incidentes de danos estruturais em edificações do tipo caixão.

Entre 1992 e 1999, foram registrados desabamentos em seis edificações, sendo os que causaram maior repercussão o Edf. Éricka e o Bloco B do Conjunto Enseada de Serrambi, ambos em Olinda.

Os problemas estruturais registrados nos prédios tipo caixão resultaram na interdição de vários empreendimentos. Muitos foram os registros de desalojamento de famílias e, em alguns casos, houve morte de moradores destes edifícios.

No entanto, somente a partir de junho de 2005, as câmaras municipais da RMR incorporaram na Lei de Ordenamento do Uso e da Ocupação do Solo a proibição de conceder licença de construção para prédios em alvenaria autoportante.

\section{Revisão Bibliográfica}

Caporrino [1] proporciona visão concisa da patologia das anomalias dos revestimentos argamassados, analisando destes 0 comportamento de seus componentes isoladamente, bem como as correlações entre as manifestações patológicas com projeto e execução.

Já Prata et al [2] propõe abordagem técnica direcionada à problemática da Alvenaria Resistente na Região Metropolitana de Recife. Trata-se de compilação de artigos técnicos elaborados por diversos autores com experiência no assunto, nos quais são apresentados, entre outros, técnicas para vistorias das edificações, Metodologia para análise de segurança estrutural e proposta de especificação técnica dos procedimentos de reforço de alvenarias.

Buscando uma proposta que seja adequada à necessidade específica para reforço nas fundações dos prédios tipo caixão, Pires Sobrinho, C.W.A et al[3] apresenta estudadas duas formas de reforço para as fundações empregando elementos de concreto armado.

Pires Sobrinho, C.W.A et al [4] apresenta proposta para reforço das alvenarias autoportantes ao analisar a influência do revestimento, simples e armado no comportamento de paredinhas em alvenaria de blocos cerâmicos de vedação.

A NBR 15812(Alvenaria estrutural - Blocos cerâmicos) [5], por tratar de tipologia assemelhada, passou a ser importante balizador normativo para a análise da concepção estrutural de projetos em Alvenaria Resistente, considerando que nunca contaram com Norma específica. 


\section{Estudo de caso}

\subsection{Caracterização do \\ Empreendimento em Estudo}

De acordo com relatório Técnico No057.718(2011) elaborado pelo Instituto de Tecnologia de Pernambuco - ITEP, o edifício em análise, localizado em conjunto residencial composto por nove blocos, possui aproximadamente 15 anos de construído, estruturada em alvenaria resistente (Prédio Caixão) com 04(quatro) pavimentos, com de 16 (dezesseis) unidades habitacionais. Cada apartamento tipo com os seguintes ambientes: 2 (dois) quartos sociais, 1 (um) banheiro social, sala para 2 ambientes, cozinha américa e área de serviço, como apresentado nas Figuras 1 e 2 .

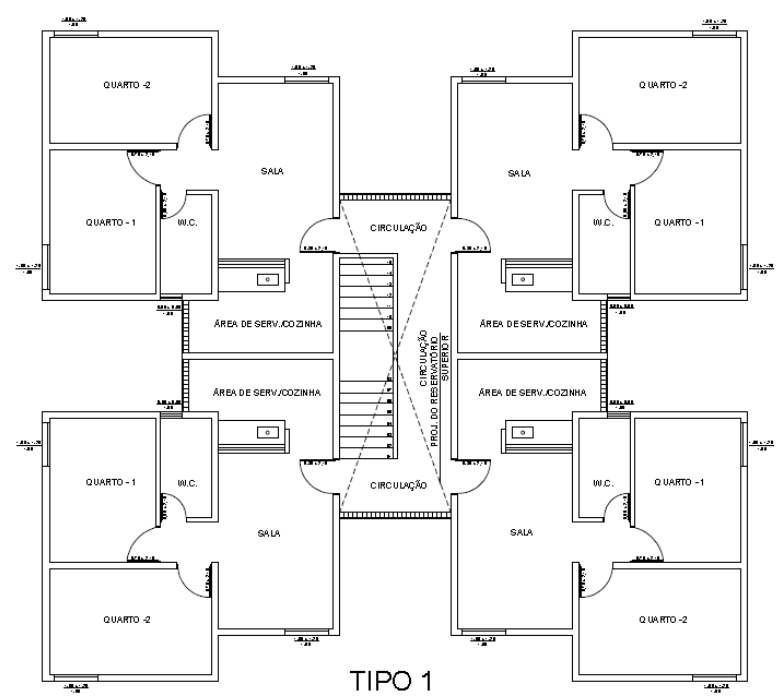

Figura 1: Pavimento Tipo Fonte: ITEP- Relatório Técnico No Técnico No 057.718 2011

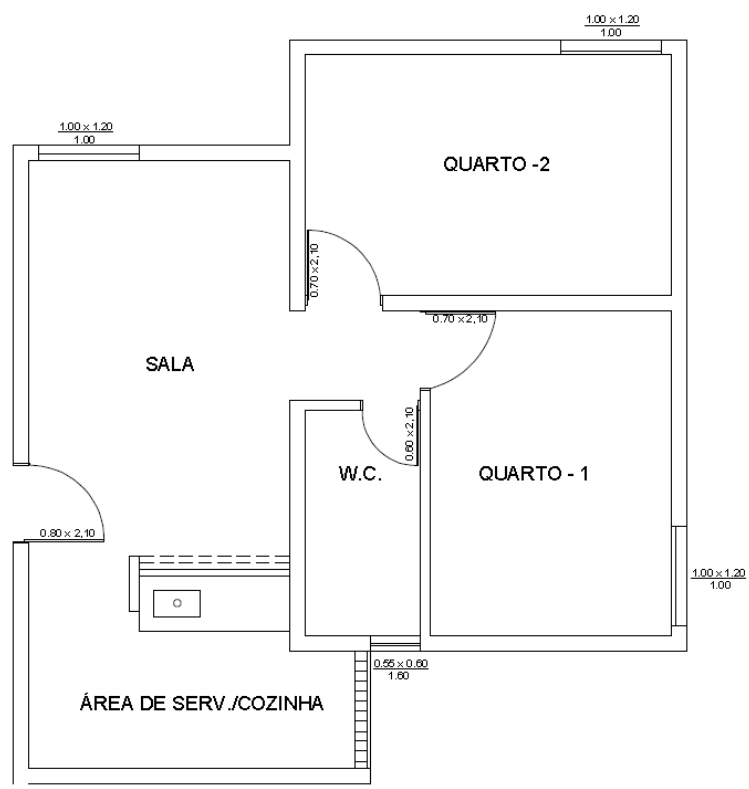

Figura 2: Planta Baixa Unidade Padrão Fonte: ITEP- Relatório Técnico No Técnico No 057.718 2011

O esquema do embasamento da fundação, constituído em alvenaria de blocos cerâmicos de 6 furos, sem revestimento, com os blocos assentados deitados, com argamassa de cimento sobre sapata corrida de concreto em formato de TE invertido, sob laje concretada. O caixão interno da fundação é preenchido com aterro de aproximadamente $0,85 \mathrm{~m}$ de altura é apresentado na Figura 3.

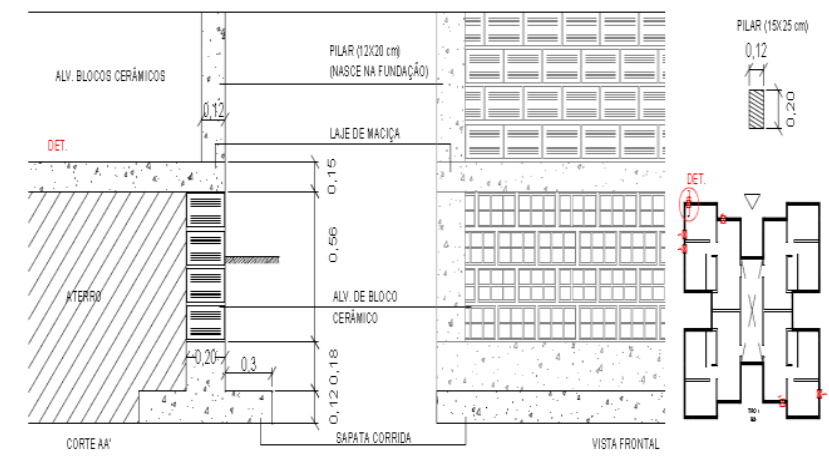

Figura 3: Detalhe das fundações

Fonte: ITEP- Relatório Técnico No Técnico No 057.718 2011

As lajes dos pavimentos tipo são maciças, amarradas nos pilares de contorno e apoiadas sobre cintas de concreto armado nas dimensões $15 \times 20 \mathrm{~cm}$. A caixa de escada, que dá sustentação ao reservatório superior, é aporticada em 
concreto armado com fundação em sapatas isoladas.

O sistema de esgotamento sanitário e fossa, as caixas de inspeção de esgoto são localizadas próximas a fundação da edificação, com uma distância aproximada de 0,5 a $0,70 \mathrm{~m}$.

A edificação possui reservatório inferior a uma distância aproximada de 0,95 m.

\subsection{Manifestações patológicas observadas}

O edifício em apreço apresenta manifestações patológicas típicas de uma edificação em alvenaria resistente.

\section{- Áreas Comuns}

Manchas e sinais de desgaste do revestimento das fachadas, devido a deficiência da pintura agravada pelo tempo e falta de manutenção, observadas em todos os blocos, o que prejudica ainda mais a estanqueidade do revestimento, provocando infiltração, ver fotos 01 a 03.

Fachadas com fluxo de água inadequado estão constantemente expostas à umidade e a proliferação de fungos é comum nesta situação. A menor exposição ao sol tende a intensificar a ocorrência desta manifestação patológica [1].

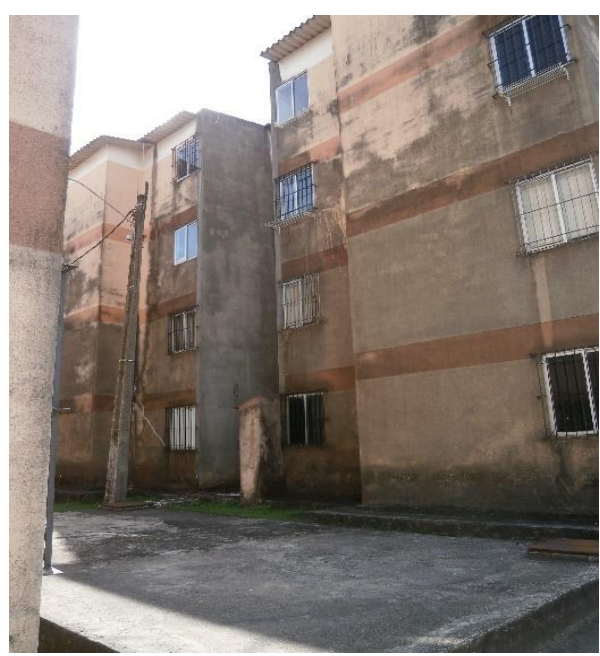

Foto 01: Degradação da Fachada

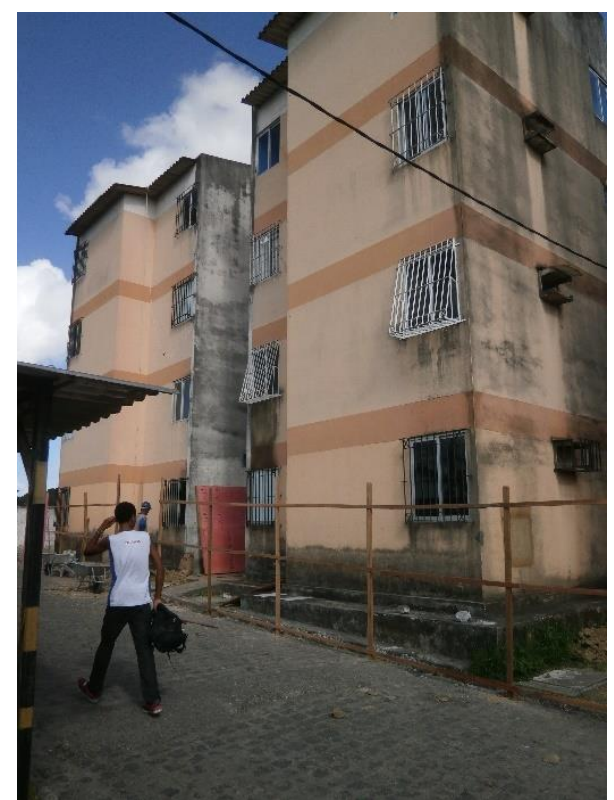

Foto 02: Degradação da Fachada.

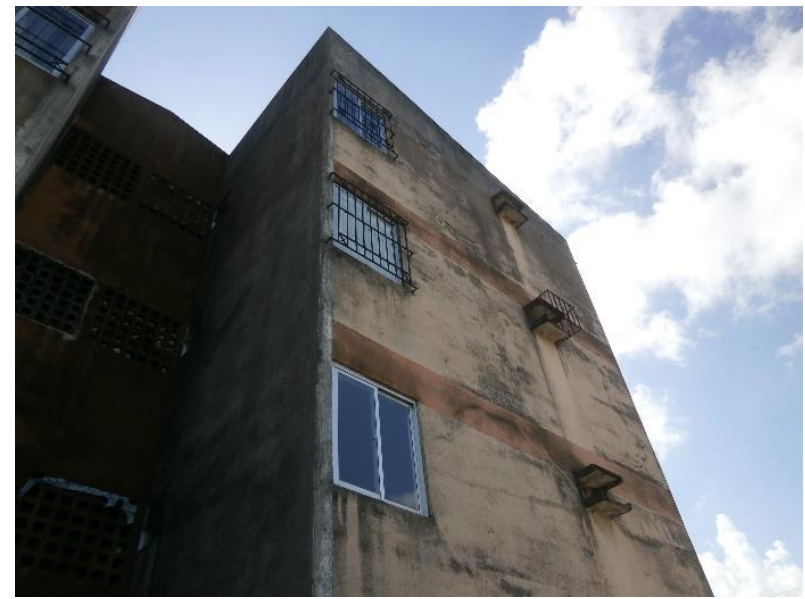

Foto 03: Degradação da Fachada

A coberta apresenta algumas telhas quebradas e/ou mal encaixadas. As telhas quebradas e a deficiência do sistema de impermeabilização da laje e calhas estão causando infiltrações nas lajes dos últimos pavimentos, como apresentado na foto 04 . 


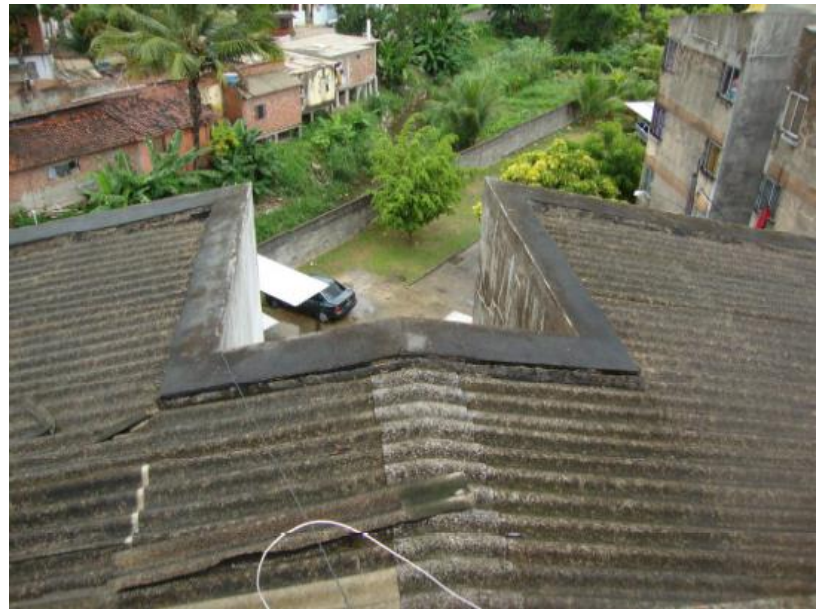

Foto 04: Coberta

Em relação ao reservatório inferior, foram encontrados vazamentos, sendo necessária a revisão do sistema de impermeabilização.

- Área Interna dos Apartamentos

Foi observado fissuras linear nas lajes de alguns apartamentos em várias direções, isso, possivelmente ocorreu devido a flexão da laje.

A ausência, ou o mau dimensionamento de vergas e contravergas é a provável causa de fissuras a $45^{\circ}$ observadas nas janelas de todas as fachadas, como observado na foto 05.

Coporrino [1] destaca que, com o esforço de compressão, as fissuras tendem a se desenvolver a partir do ponto de maior concentração das tensões, o vértice das aberturas.

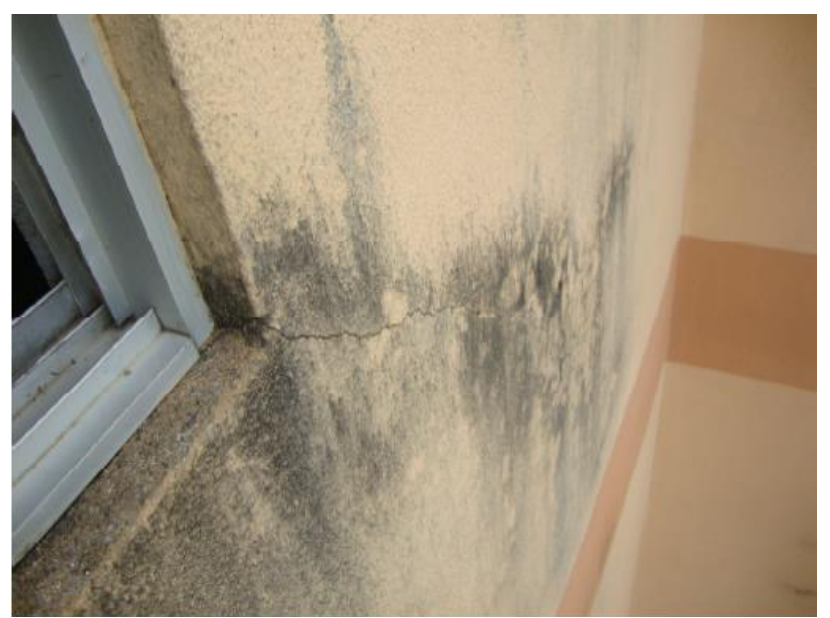

Foto 05: Ausência de Vergas e Contravergas

Foram observadas manchas de umidade na área das janelas por infiltração decorrente de águas de chuva através da esquadria.

Infiltração decorrente de águas de chuva através do cobogó das áreas de serviços e hall de

60 escada.

Nas áreas de banheiros e cozinha em alguns apartamentos foram observados vazamentos devido ao mau funcionamento do sistema hidráulico.

Manchas de umidade por infiltração decorrente de aguas de chuva através do revestimento externo, isto está ocorrendo por desgaste da pintura de proteção da fachada exemplo ver foto 28;

Manchas de infiltração por ascensão capilar foram observadas em alguns apartamentos, como indicado na foto 6 .

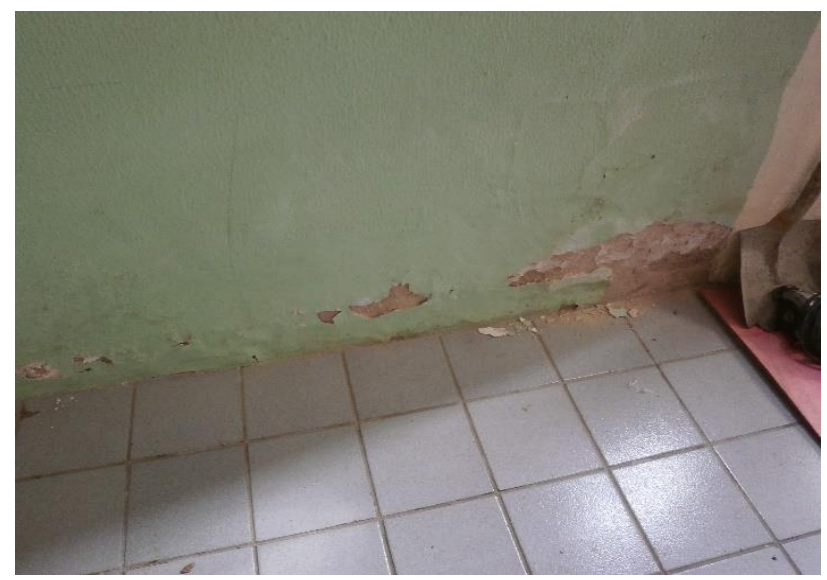

Foto 06: Infiltração por ascensão capilar

Infiltração nas lajes de alguns apartamentos dos últimos pavimentos.

Importante registrar que não foram observadas reformas.

\subsection{Análise de segurança estrutural}

A análise de segurança estrutural de uma edificação em alvenaria resistente, por não possuir norma especifica foi adotada como referência os principais requisitos constantes na NBR 15812/2010 [3].

Alvenaria estrutural-blocos cerâmicos, por ser a mais próxima existente e a NBR 8681/2003Ações e segurança de estruturas-procedimento.

Os resultados a seguir foram obtidos no Relatório Técnico No057.718 ITEP(2011) [4]

- Tensões solicitantes

A análise estrutural foi realizada utilizando uma modelagem numérica tendo por base 0 método dos elementos finitos para obtenção das tensões atuantes, considerando as densidades dos http: / / dx.doi.org/10.25286/repa.v3i2.886 
Ensaio à Compressão:

elementos construtivos levantados em amostras representativas da edificação e os coeficientes de segurança de Norma.

\section{- Tensões resistentes}

A resistência característica dos prismas $\left(f_{p}\right)$ foi obtida dos ensaios de resistência a compressão das amostras retiradas das paredes da superestrutura e em alguns casos, blocos A, B, e $F$, também do embasamento da fundação.

As tensões resistentes para os elementos de parede da superestrutura e da infraestrutura foram obtidas em ensaios de resistência a compressão em amostras representativas do conjunto dos edifícios que compõe o Conjunto Residencial. Amostras nas dimensões de $(50 \mathrm{~cm} \times 50 \mathrm{~cm})$ retirados com equipamento de corte com disco duplo e transportado sobre colchoes de areia, travados entre si, até o ITEP onde receberam aparelhamento de corte em disco sobre bancada, em seguida capeados na direção do atual carregamento.

Para as paredes da superestrutura foram retirados amostras dos sete blocos do Conjunto totalizando dezesseis amostras, sendo constatado que foram constituídas de mesmo material.

Dos embasamentos em alvenaria das fundações, de três blocos com este tipo de embasamento, foram retirados seis amostras de cada totalizando dezoito amostras.

Os resultados dos ensaios das amostras estão apresentados na Tabela 01.

Tabela 01: Resultados dos Ensaios à Compressão (RT 057.718. ITEP)

Fonte: ITEP- Relatório Técnico No Técnico No 057.718 2011

\subsection{Projeto de reforço das alvenarias de embasamento do BLOCO "A" (TIPO 1)}

De acordo com Pires Sobrinho [5], ensaios realizados mostram que há uma melhoria significativa na capacidade de carga das

\begin{tabular}{|c|c|c|c|c|c|c|c|c|c|}
\hline \multirow{2}{*}{$\mathrm{CP}$} & \multirow{2}{*}{$\begin{array}{c}\text { Tipo de } \\
\mathrm{CP}\end{array}$} & \multirow{2}{*}{ Localização } & \multicolumn{3}{|c|}{ Dimensões $(\mathrm{cm})$} & \multirow{2}{*}{$\begin{array}{c}\text { Massa } \\
(\mathrm{kg})\end{array}$} & \multirow{2}{*}{$\begin{array}{c}\text { Densidade } \\
\left(\mathrm{kg} / \mathrm{cm}^{3}\right)\end{array}$} & \multirow{2}{*}{ Carga $(\mathbb{N})$} & \multirow{2}{*}{$\begin{array}{l}\text { Resistência } \\
\text { (Mpa) }\end{array}$} \\
\hline & & & $\mathrm{C}$ & $\mathrm{L}$ & $\mathrm{H}$ & & & & \\
\hline $\mathrm{A} 01$ & Prisma & Superestrutura & 44,5 & 12,5 & 45,0 & 30,7 & 0,00122647 & 79270 & 1,43 \\
\hline $\mathrm{A} 02$ & Prisma & Superestrutura & 45,0 & 12,5 & 41,0 & 28,5 & 0,00123577 & 109230 & 1,94 \\
\hline B 01 & Prisma & Superestrutura & 41,0 & 14,0 & 46,0 & 36,1 & 0,00136722 & 88080 & 1,53 \\
\hline $\mathrm{B} 02$ & Prisma & Superestrutura & 42,0 & 14,0 & 46,5 & 38,5 & 0,00140809 & 115050 & 1,96 \\
\hline $\mathrm{Co1}$ & Prisma & Superestrutura & 48,5 & 13,0 & 47,0 & 38,0 & 0,00128233 & 112000 & 1,78 \\
\hline $\mathrm{C02}$ & Prisma & Superestrutura & 46,0 & 12,0 & 31,0 & 23,8 & 0,00139084 & 54680 & 0,99 \\
\hline $\mathrm{CO}$ & Prisma & Superestrutura & 46,0 & 12,5 & 32,0 & 23,1 & 0,00125543 & 90880 & 1,58 \\
\hline $\mathrm{CO} 04$ & Prisma & Superestrutura & 46,5 & 13,5 & 46,0 & 36,3 & 0,00125708 & 90770 & 1,45 \\
\hline $\mathrm{CO} 05$ & Prisma & Superestrutura & 47,5 & 11,0 & 42,5 & 21,6 & 0,0009727 & 85820 & 1,64 \\
\hline $\mathrm{C} 06$ & Prisma & Superestrutura & 45,0 & 12,5 & 46,0 & 33,7 & 0,00130242 & 121590 & 2,16 \\
\hline D 01 & Prisma & Superestrutura & 46,0 & 12,5 & 47,0 & 33,4 & 0,00123589 & 152030 & 2,64 \\
\hline E 01 & Prisma & Superestrutura & 45,0 & 14,0 & 48,0 & 42,3 & 0,00139881 & 136480 & 2,17 \\
\hline $\mathrm{E} 02$ & Prisma & Superestrutura & 44,0 & 14,0 & 46,0 & 38,8 & 0,00136928 & 118530 & 1,92 \\
\hline $\mathrm{F} 01$ & Prisma & Superestrutura & 45,0 & 13,0 & 47,0 & 35,8 & 0,00130205 & 88540 & 1,51 \\
\hline I 01 & Prisma & Superestrutura & 45,0 & 12,0 & 48,0 & 31,6 & 0,00121914 & 129690 & 2,40 \\
\hline $\mathrm{I} 02$ & Prisma & Superestrutura & 45,0 & 13,0 & 48,0 & 34,1 & 0,00121439 & 102310 & 1,75 \\
\hline A 01 & Prisma & Infraestrutura & 41,0 & 22,0 & 32,0 & 43,4 & 0,0015036 & 226310 & 2,51 \\
\hline A 02 & Prisma & Infraestrutura & 40,0 & 20,0 & 27,0 & 33,0 & 0,00152778 & 75820 & 0,95 \\
\hline A 03 & Prisma & Infraestrutura & 47,0 & 21,0 & 29,0 & 40,4 & 0,00141145 & 104040 & 1,05 \\
\hline $\mathrm{A} 04$ & Prisma & Infraestrutura & 40,0 & 20,0 & 25,0 & 28,8 & 0,00144 & 87750 & 1,10 \\
\hline A 05 & Prisma & Infraestrutura & 42,5 & 21,0 & 35,0 & 40,5 & 0,00129652 & 78400 & 0,88 \\
\hline A 06 & Prisma & Infraestrutura & 40,0 & 20,0 & 36,0 & 44,7 & 0,00155208 & 127880 & 1,60 \\
\hline B 01 & Prisma & Infraestrutura & 31,0 & 19,0 & 28,0 & 26,3 & 0,00159471 & 59750 & 1,01 \\
\hline B 02 & Prisma & Infraestrutura & 40,0 & 20,0 & 32,0 & 38,2 & 0,00149219 & 123300 & 1,54 \\
\hline В 03 & Prisma & Infraestrutura & 42,0 & 20,0 & 34,0 & 45,5 & 0,00159314 & 155800 & 1,85 \\
\hline В 04 & Prisma & Infraestrutura & 37,0 & 19,0 & 29,0 & 32,4 & 0,00158925 & 114810 & 1,63 \\
\hline B 05 & Prisma & Infraestrutura & 40,0 & 20,0 & 30,0 & 35,9 & 0,00149583 & 103000 & 1,29 \\
\hline B 06 & Prisma & Infraestrutura & 38,0 & 20,0 & 38,0 & 44,4 & 0,0015374 & 106480 & 1,40 \\
\hline F 01 & Prisma & Infraestrutura & 32,0 & 20,0 & 36,0 & 32,3 & 0,00140191 & 59790 & 0,93 \\
\hline $\mathrm{F} 02$ & Prisma & Infraestrutura & 37,0 & 20,0 & 35,0 & 39,4 & 0,00152124 & 75210 & 1,02 \\
\hline $\mathrm{F} 03$ & Prisma & Infraestrutura & 42,0 & 20,0 & 28,0 & 37,1 & 0,00157738 & 48930 & 0,58 \\
\hline F 04 & Prisma & Infraestrutura & 44,0 & 20,0 & 31,0 & 41,5 & 0,00152126 & 157330 & 1,79 \\
\hline F 05 & Prisma & Infraestrutura & 38,0 & 20,0 & 36,0 & 39,7 & 0,00145102 & 119730 & 1,58 \\
\hline F 06 & Prisma & Infraestrutura & 36,0 & 20,0 & 30,0 & 33,4 & 0,0015463 & 82650 & 1,15 \\
\hline
\end{tabular}

OBS. : a) Ensaio realizado em 17/05/11 com base nas NBR-7184 e 8215 da ABNT.

fundações com a introdução dos reforços através da incorporação de placas de concreto laterais aos embasamentos das fundações das edificações em alvenaria.

As alvenarias de embasamento referentes às paredes de cotas $\mathrm{x}=3,8$ e $\mathrm{x}=11,94$ precisaram ser reforçadas, pois apresentam tensões de compressão em torno de $0,40 \mathrm{MPa}$, superiores a tensão resistente do embasamento $\sigma_{\mathrm{Rd}}=0,25$ MPa.

As alvenarias de embasamento referentes às paredes de cotas y $=2,55$ e y $=11,99$ precisaram ser reforçadas, pois apresentam tensões de compressão em torno de $0,38 \mathrm{MPa}$, superiores a tensão resistente do embasamento $\sigma_{R d}=0,25$ MPa.

Considerando que os colapsos ocorridos nesse tipo de tipologia construtiva sofreram significativa influência da deterioração dos materiais constituintes das alvenarias de embasamento devido à ação da EPU (expansão por umidade em tijolos cerâmicos); considerando ainda que esses embasamentos não se encontram revestidos, e também que a resistência característica estimada da amostra (fpk,est) equivale a $64 \%$ daquela da alvenaria de elevação, é imprescindível levar em conta a hipótese de perda de desempenho desses componentes com a umidade natural do terreno 
(ou das águas provenientes de elevação do nível do lençol freático durante o inverno) e com o passar do tempo;

Assim sendo, recomendou-se o envelopamento de todas as alvenarias de embasamento, com placa de concreto simples ( $\mathrm{fck}=20 \mathrm{MPA}$ ) com $7 \mathrm{~cm}$ de espessura, sobre a viga de base elástica (viga Tê invertida) e travada com estribos transversais no seu topo, conforme indicação em projeto, conforme apresentado nas Figuras 3 a 5.

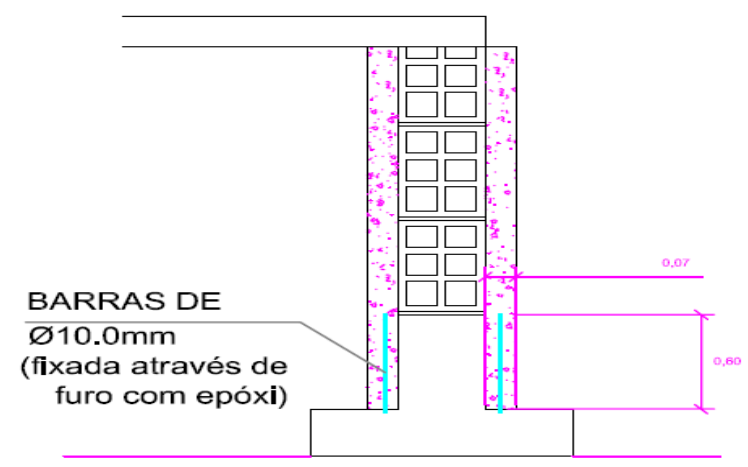

CORTE TRANSVERSAL

Figura 3: Reforço das Fundações Fonte: ITEP- Relatório Técnico No Técnico No 057.718 2011

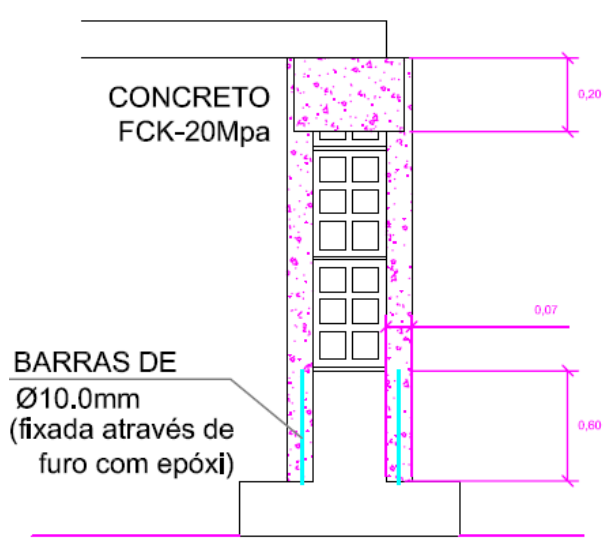

CORTE TRANSVERSAL

Figura 4: Reforço das Fundações Fonte: ITEP- Relatório Técnico No Técnico No 057.718 2011

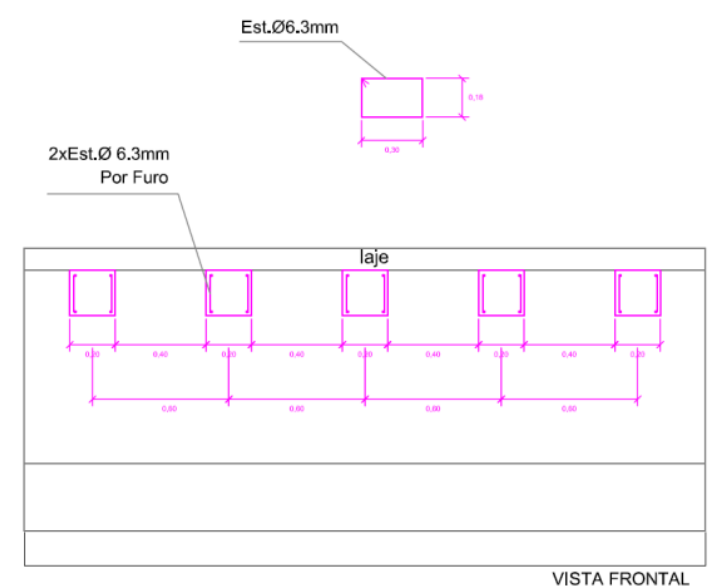

Figura 5: Reforço das Fundações Fonte: ITEP- Relatório Técnico No Técnico No 057.718 2011

\subsection{Das alvenarias de elevação - $1^{0}$ Pavimento (Pavimento Térreo)}

Segundo Pires Sobrinho, C.W.A et Al [6], o revestimento em argamassa nas paredes de alvenaria produz um aumento da capacidade resistente e da rigidez das paredes, sendo este incremento crescente com a espessura e ao maior consumo de cimento da argamassa.

A incorporação de revestimento em argamassa não altera a forma de ruptura das alvenarias, que acontece de forma brusca, porém sendo constatado que há uma efetiva participação do 
revestimento no comportamento compressivo de paredes.

Ainda segundo o autor, o reforço com telas, com efetivo travamento e revestimento, além de elevar a capacidade resistente das paredes, produz mudança significativa nas suas formas de ruptura. Observou-se que as "paredinhas" reforçadas com tela, embora apresentando ruptura brusca, não colapsam, mostram uma certa reserva de resistência na fase pós-pico.

As alvenarias de elevação do 10 Pavimento (Pavimento Térreo) referentes às paredes de cotas $\mathrm{x}=3,8$ e $\mathrm{x}=11,94$, precisaram ser reforçadas, pois apresentam tensões de compressão em torno de $0,60 \mathrm{MPa}$, superiores a tensão resistente da alvenaria de elevação $\sigma_{R d}=$ $0,35 \mathrm{MPa}$.

As alvenarias de elevação do 10 Pavimentos (Pavimento Térreo) referentes às paredes de cotas $\mathrm{y}=2,55$ e $\mathrm{y}=11,99$, precisaram ser reforçadas, pois apresentam tensões de compressão em torno de $0,57 \mathrm{MPa}$, superiores a tensão resistente da alvenaria de elevação $\sigma_{R d}=$ 0,35 Mpa, de acordo com a Figura 6.

As alvenarias de elevação dos demais pavimentos, isto é, dos $20,3^{\circ}$ e $4^{\circ}$ Pavimentos não necessitaram de reforço.

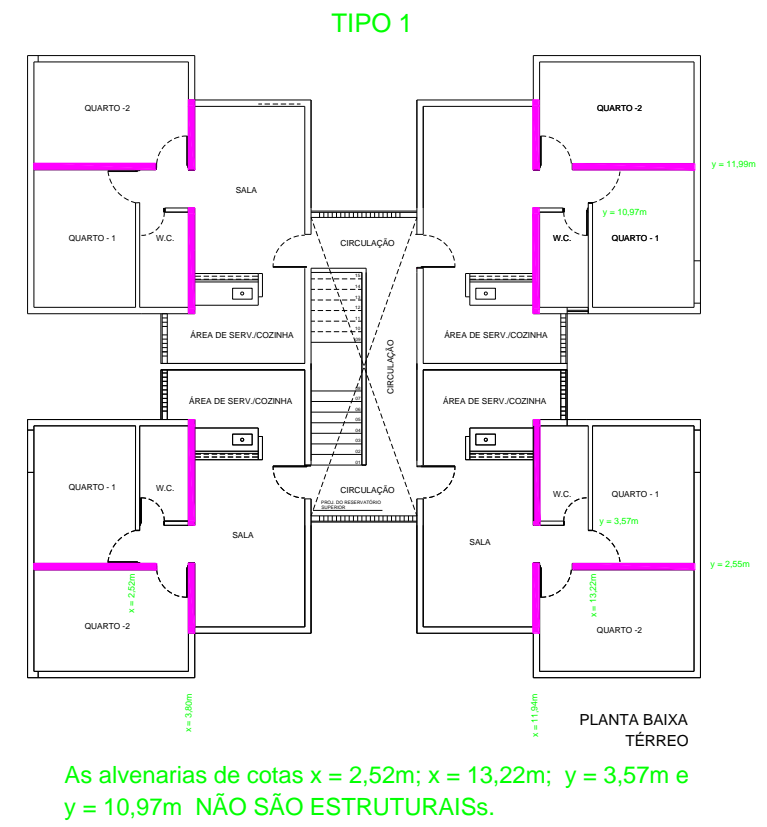

Figura 6: Alvenarias a serem reforçadas Fonte: ITEP- Relatório Técnico No Técnico No 057.718 2011

Assim sendo, recomenda-se a incorporação de reforço com malha Q138 (2 x $\varnothing 4.2$ c 10) argamassada (fa $\pm 4,5 \mathrm{MPa}$ ) e travada a cada $20 \mathrm{~cm}$ com conectores de $\varnothing 6.0$, para as alvenarias do 10 Pavimento (Pavimento Térreo), conforme detalhe apresentado na figura 7 .

\section{SUPERESTRUTURA}

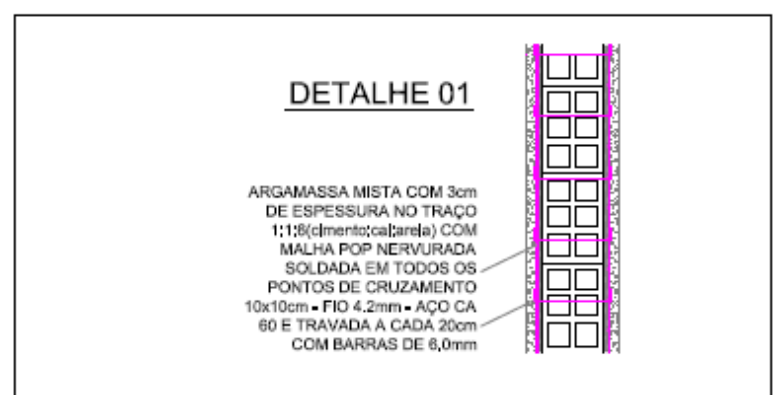

Figura 7: Reforço na Superestrutura Fonte: ITEP- Relatório Técnico No Técnico No 057.718 2011

\section{Execução dos Reforços}

Para início dos serviços de recuperação e reforço estrutural, foi necessária a desocupação temporária de todas as 16 unidades habitacionais do edifício.

Como os demais 8 edifícios do Conjunto Residencial ainda permaneceram ocupados, foi necessária a execução de tapume isolando a obra, como verificado na foto 6 .

Com o objetivo de evitar fragilizar sua estrutura, foi estabelecido que os trabalhos seriam realizados em apenas duas unidades habitacionais por vez.

Foram abertas valas no interior dos apartamentos do térreo para permitir a exposição das alvenarias de embasamento, fotos 7 e 8 .

Antes da aplicação da malha especificada em projeto, foram removidos os revestimentos das paredes. 


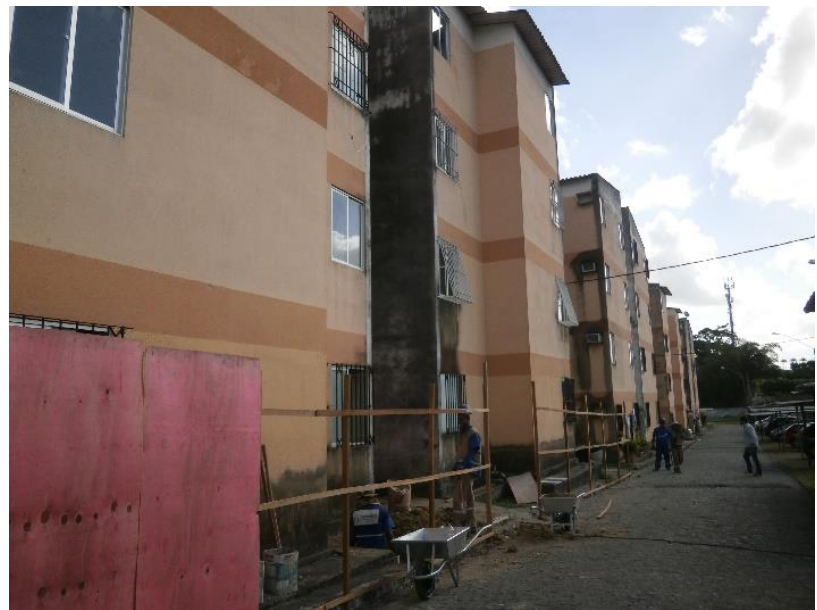

Foto 06: Montagem do Tapume

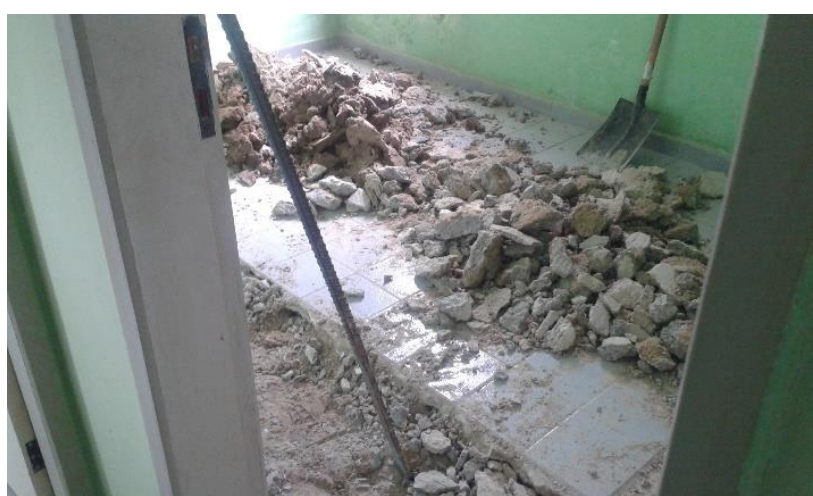

Foto 07: Remoção dos revestimentos

O confinamento das áreas de trabalho foi um dificultador para a execução dos serviços.

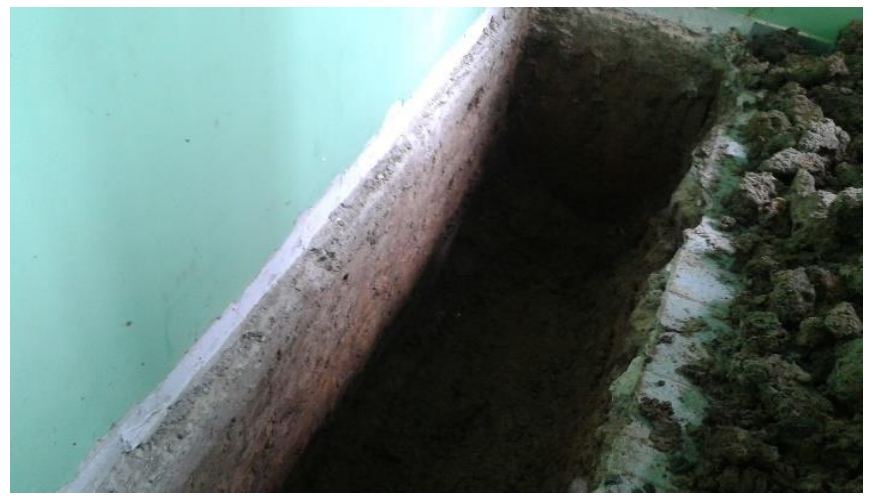

Foto 08: Exposição da Alvenaria de Embasamento

Conforme apresentado no Laudo elaborado pelo ITEP, verificou-se a ausência de revestimento nas alvenarias de embasamento.

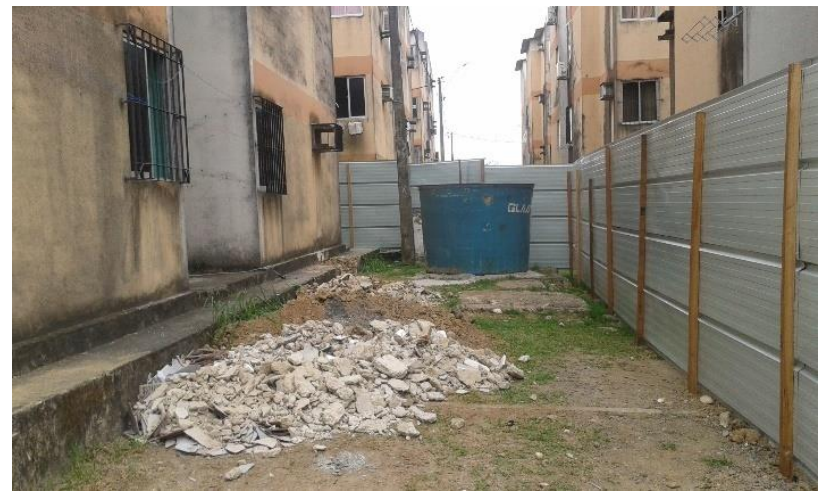

Foto 09: Retirada dos Entulhos Gerados

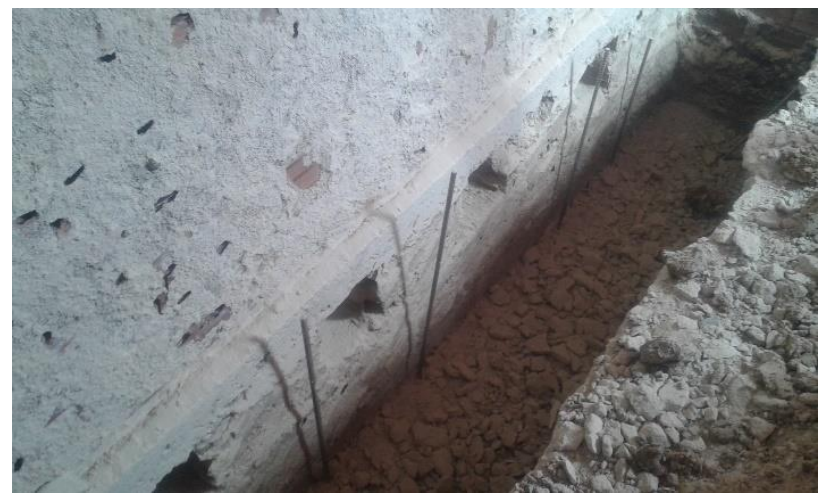

Foto 10: Abertura dos "tufos" de $20 \mathrm{~cm} \times 20 \mathrm{~cm}$

Em todos os banheiros do pavimento térreo foi realizada revisão geral das instalações de água e esgoto, com a substituição de componentes, quando necessário.

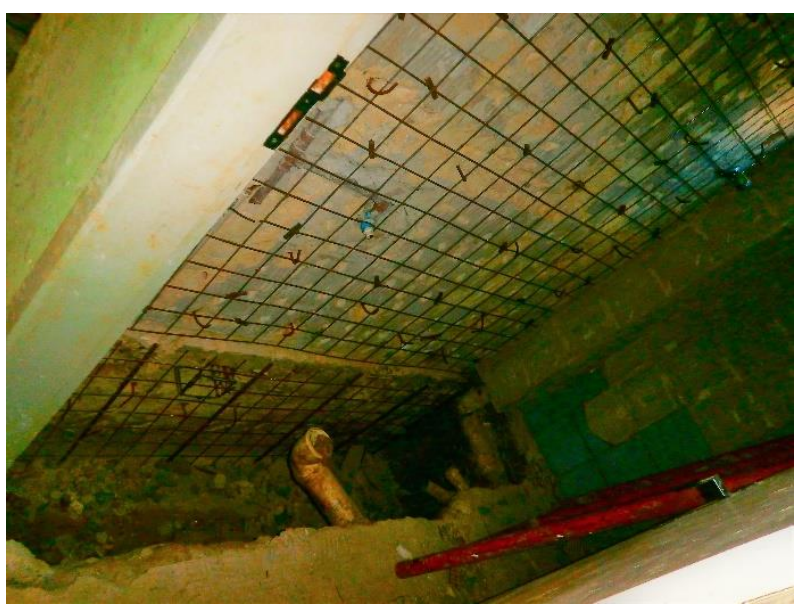

Foto 11: Recuperação das Instalações Prediais 


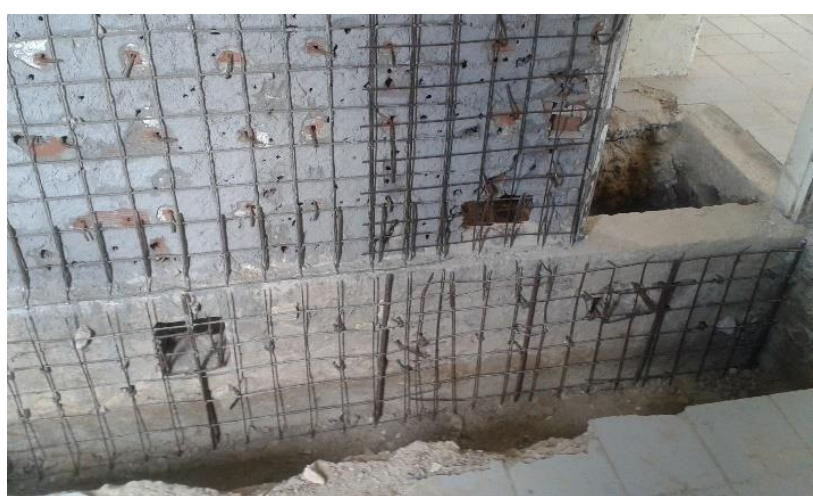

Foto 12: Montagem do reforço do embasamento

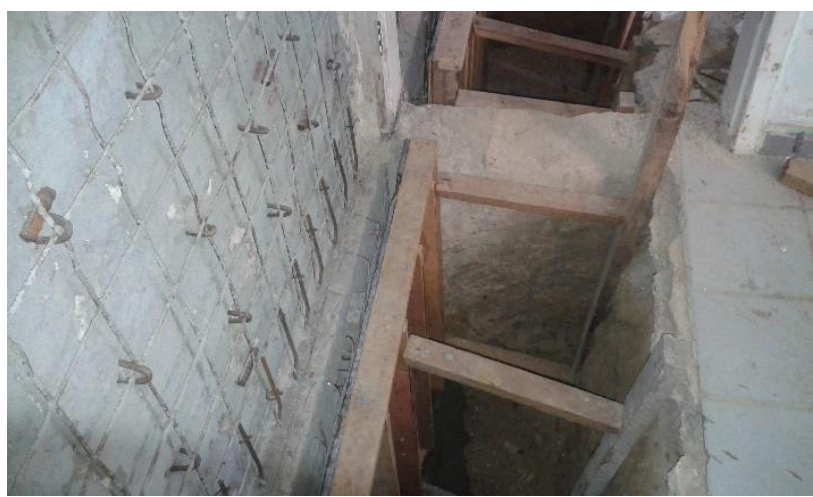

Foto 13: Preparação para concretagem

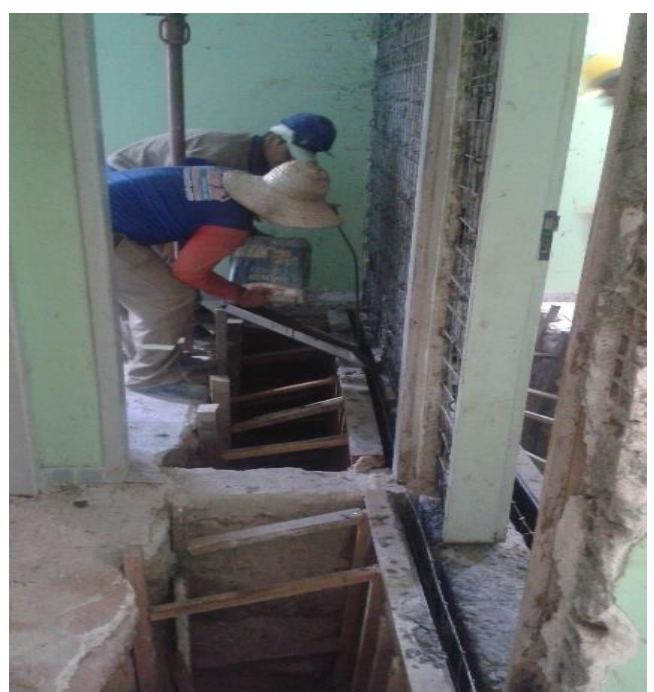

Foto 14: Preenchimento das formas

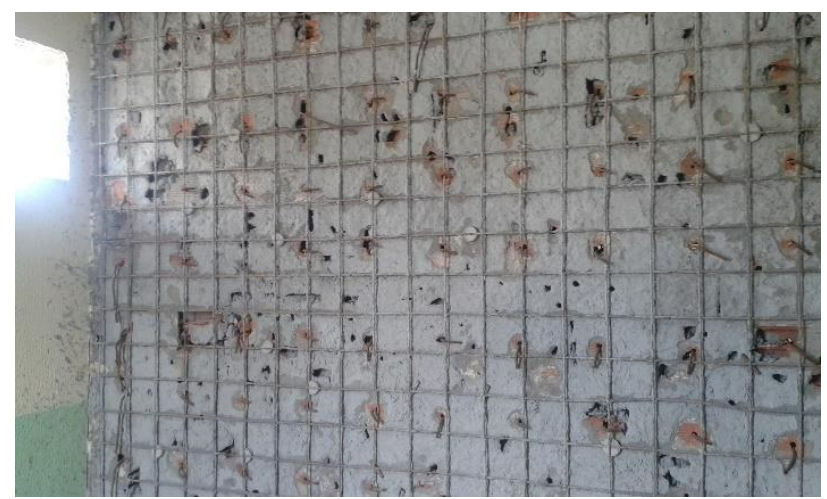

Foto 15: Reforço das Alvenarias de Elevação

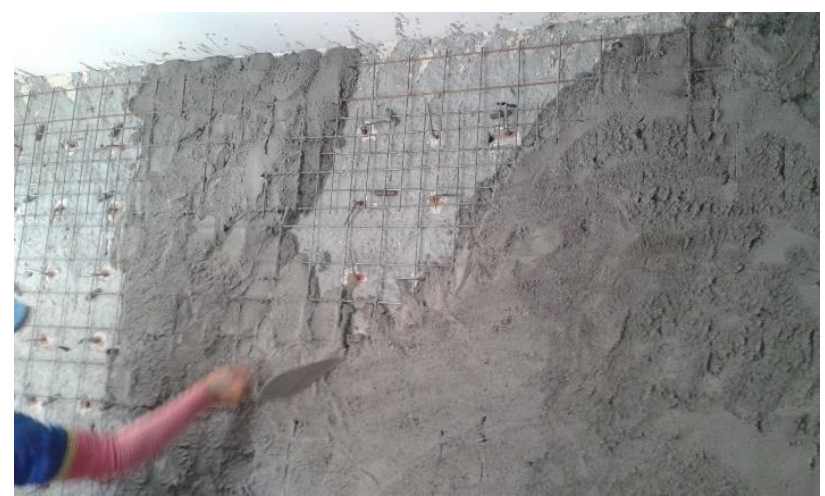

Foto 16: Aplicação da Argamassa

Recomendou-se a aplicação da argamassa em pano único.

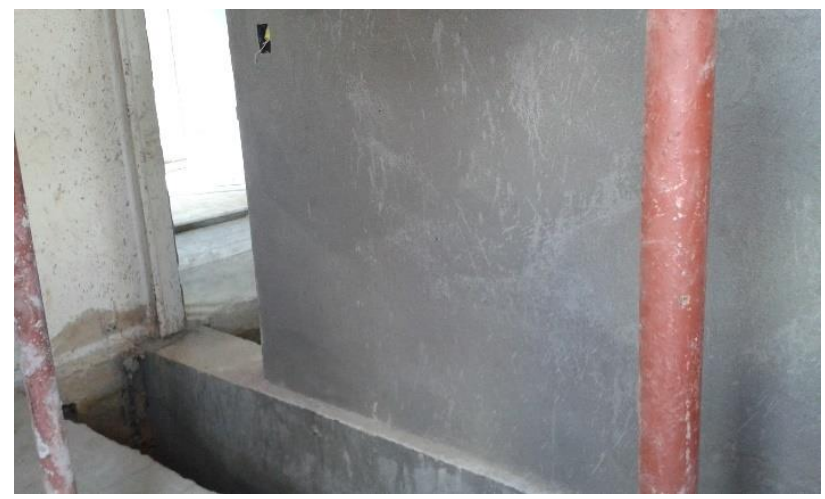

Foto 17: Alvenaria Interna Reforçada 


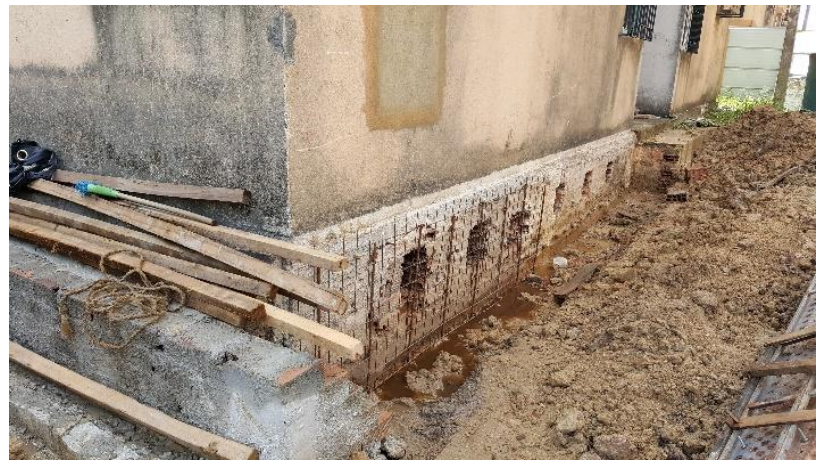

Foto 18: Reforço das Alvenarias de Periferia

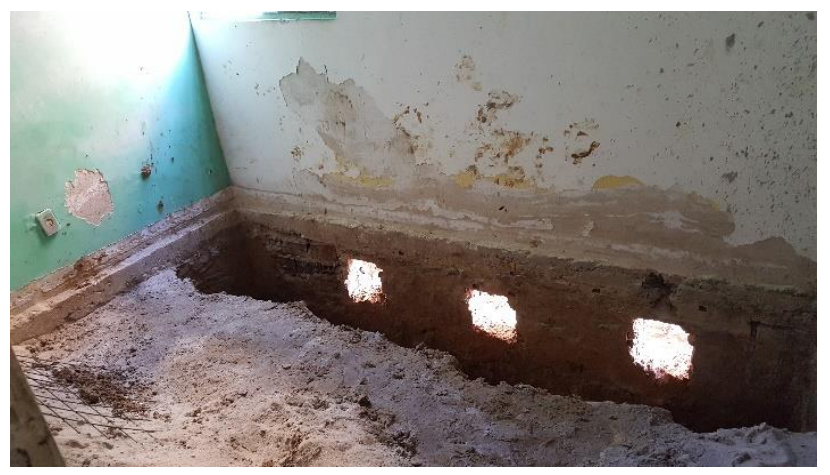

Foto 19: Reforço das Alvenarias de Periferia

$\mathrm{Na}$ fachada, antes da aplicação do Emboço Paulista, na faixa de $50 \mathrm{~cm}$ acima da laje Radier (calçada) foi retirada a argamassa em todo perímetro externo do edifício, após lavagem completa desta faixa, com jato de alta pressão, em toda a área utilizando uma mistura de água + água sanitária na proporção de 1:1. Após enxágue, aplicou-se 03 (três) demãos de argamassa polimérica semi flexível à base de cimentos especiais, espaçadas de 08 (oito) horas entre cada demão, sendo a última demão aplicada sobre a tela de poliéster, após secagem de 08 (oito) horas, com posterior aplicação de mais duas demãos cruzadas sobre a tela. Fotos 20 e 21.

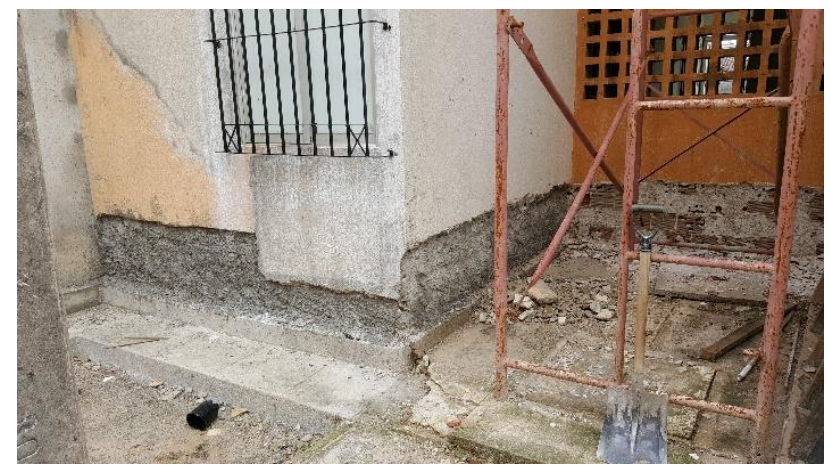

Foto 20: Recuperação das Fachadas

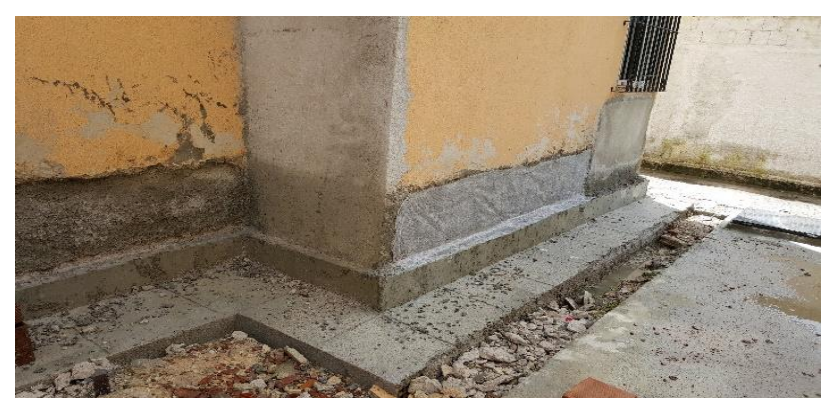

Foto 21: Recuperação das Fachadas

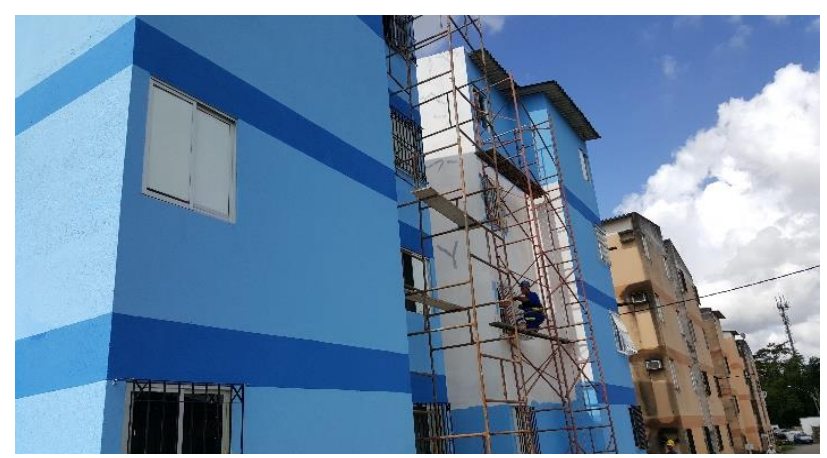

Foto 21: Recuperação das Fachadas

Nas fachadas, nos locais onde foram verificadas fissuras e trincas passantes, foram aplicadas Telas Eletrosoldadas em ambos os lados da parede, ao longo do eixo da fissura, com transpasse de $20 \mathrm{~cm}$ para cada um dos lados da fissura/rachadura/trinca, com largura total de 40 $\mathrm{cm}$, fixadas rente à alvenaria por grampos galvanizados.

Fissuras de menor intensidade foram tratadas com a aplicação de mastique acrílico ou tela de poliéster, dependendo da profundidade das fissuras, bem como das condições de aderência do revestimento existente.

A recuperação da coberta foi realizada com aplicação de Manta Asfáltica Aluminizada para http: / / dx.doi.org/10.25286/repa.v3i2.886 
Telhados sobre os rufos e as telhas de forma a vedar a abertura existente entre estas peças em todos os encontros de telhas com paredes, como apresentado na Foto 22.

As telhas quebradas foram substituídas.

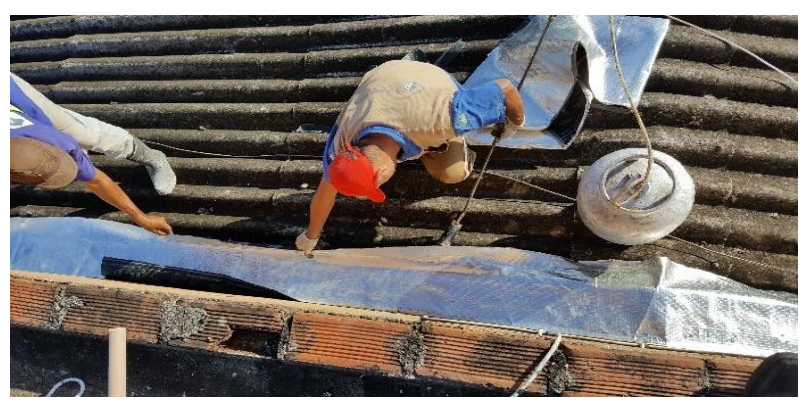

Foto 22: Recuperação da obra.

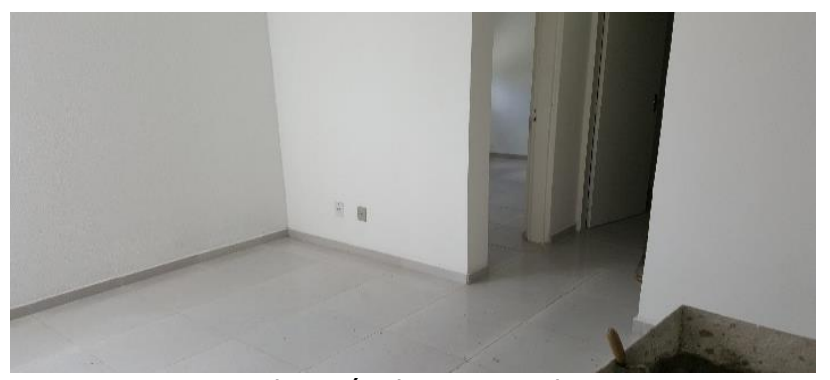

Foto 23: Interior do Imóvel Recuperado.

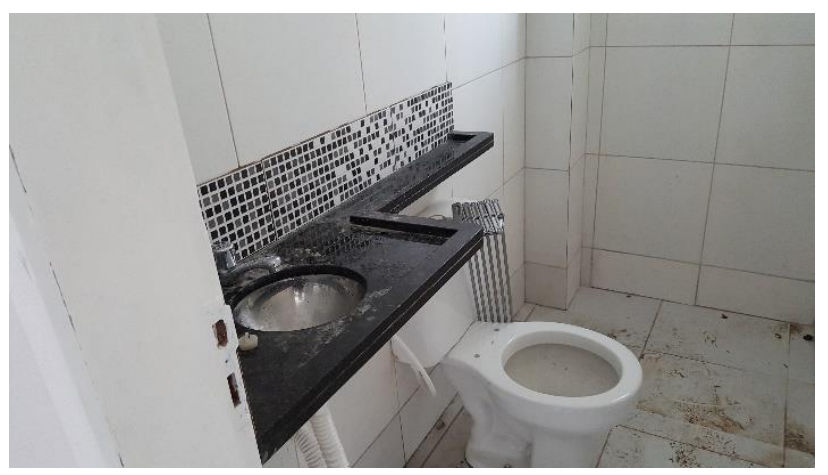

Foto 24: Interior de Imóvel Recuperado

\section{Resultados}

O prédio caixão objeto de nosso estudo - Bloco A - está inserido em um conjunto residencial composto por 9 blocos.

Apresentamos a seguir, os custos estimados para a execução da recuperação estrutural de Prédio Caixão, considerando a hipótese de contratação de empresa de Engenharia para execução dos serviços necessários apenas ao Bloco A.

Vale destacar que, ao contratar-se a recuperação de quantidade maior de prédios, o custo orçado por bloco tende a ser reduzindo.

Os custos apresentados abaixo, visando a simplificação do relatório, apresentam arredondamentos de atéErro! Fonte de referência não encontrada. $1 \%$.

O cronograma estima a conclusão dos serviços em 2 meses.

A realização de ensaios e elaboração de Projeto de Recuperação custou aproximadamente $\mathrm{R} \$ 30.000,00$. A parcela referente ao Bloco $A$ foi de $R \$ 3.300,00$.

O orçamento-base utilizado para contratação da recuperação indica um custo total de $R \$$ $1.600 .000,00$, representando para o Bloco A, devido à suas necessidades específicas de reforço, $\mathrm{R} \$ 250.000,00$.

Considerando a necessidade de mantermos o bloco totalmente desocupado por 2 meses, faz-se necessário prever o pagamento de 16 aluguéis e respectivas taxas por este período, totalizando $R \$$ $24.000,00$.

Tabela 02: Resumo de Custos Incidentes

\begin{tabular}{|l|r|}
\hline \multicolumn{1}{|c|}{ ITEM } & \multicolumn{1}{c|}{ CUSTO } \\
\hline Projetos & $\mathrm{R} \$ 3.300,00$ \\
\hline Recuperação do Bloco & $\mathrm{R} \$ 250.000,00$ \\
\hline Alugueis e Taxas & $\mathrm{R} \$ 24.000,00$ \\
\hline $\begin{array}{l}\text { Mudanças para desocupação } \\
\text { das unidades habitacionais }\end{array}$ & $\mathrm{R} \$ 80.000,00$ \\
\hline TOTAL & $\mathbf{R} \$ \mathbf{3 5 7 . 3 0 0 , 0 0}$ \\
\hline
\end{tabular}

Fonte: Autor

O custo apresentado acima representa uma cota de contribuição de aproximadamente $\mathbf{R} \$$ $\mathbf{2 2 . 5 0 0 , 0 0}$ por apartamento.

\section{Conclusões}

O reforço das alvenarias realizado provou-se tecnicamente viável. Os ensaios apresentados por Pires Sobrinho [1] [2] indicam que, caso sejam garantidas as condições originais de utilização, bem como a devida manutenção, as edificações recuperadas voltarão a apresentar níveis de segurança compatíveis com a Legislação e Normas vigentes. 
No entanto, cumpre-nos destacar que, a depender exclusivamente dos recursos arrecadados junto aos usuários, a realização dos serviços pode vir financeiramente inviável. Além dos custos diretos, devem ser previstos os valores referentes a aluguéis e custos de transporte de mobília a serem pagos para que os moradores possam desocupar a unidades pelo período necessário para conclusão dos serviços.

Desta forma, deve ser encontrada uma forma de se atribuir, de acordo com os níveis de responsabilidade, os custos a construtores responsáveis pela implantação, aos poderes públicos municipais, estadual e federal, incluindose também os respectivos moradores. Consideramos que sua participação nesta composição é imprescindível para que se consolide a necessidade de cumprimento do plano de manutenção que garantirá o prolongamento das condições de adequado desempenho das edificações e seus componentes.

Somente desta maneira, poderemos viabilizar a recuperação do passivo existente na Região Metropolitana de Recife, minimizando-se o impacto social resultante da eventual interdição de empreendimentos que venham a apresentar comprometimento de sua estabilidade estrutural.

\section{Referências}

[1] CAPORRINO, C .F. Patologia das

Anomalias em Alvenarias e Revestimentos Argamassados. São Paulo: PINI, 2015.

[2] Prata, D. G. et al. Engenharia para Prédios-caixão na Região Metropolitana de Recife. Brasília: Caixa Econômica Federal, 2012.

[3] ABNT. NBR 15812-1: Alvenaria estrutural Blocos cerâmicos. Parte 1. Rio de Janeiro, 2010.

[4] ITEP. Relatório Técnico No 057.7182011.

[5] PIRES SOBRINHO, C. W. A et al. Analise de modelo para reforços de embasamentos em alvenaria para edifícios construídos em alvenaria resistente. Congreso Internacional sobre patologya y reabilitacion de estructuras, 6., 2010, Cordoba. Anais... Cordoba, 2010.

[6] Influência do revestimento, simples e armado, no Comportamento de paradinhas em alvenaria de blocos cerâmicos de vedação. V Congreso Internacional sobre patologya y reabilitacion de estructuras, 5., 2010, Curitiba. Anais... Curitiba, 2009.

[7] ABNT. NBR 8681: Ações e segurança nas estruturas. Versão Corrigida. Rio de Janeiro, 2004. 